Article

\title{
Two-Step Azidoalkenylation of Terminal Alkenes Using Iodomethyl Sulfones
}

\author{
Nicolas Millius, Guillaume Lapointe and Philippe Renaud * ${ }^{\mathbb{C}}$ \\ Department of Chemistry and Biochemistry, University of Bern, Freiestrasse 3, CH-3012 Bern, Switzerland; \\ Nicolas.Millius@dsm.com (N.M.); guillaume.lapointe@novartis.com (G.L.) \\ * Correspondence: philippe.renaud@dcb.unibe.ch \\ Academic Editor: Chryssostomos Chatgilialoglu \\ Received: 31 October 2019; Accepted: 11 November 2019; Published: 18 November 2019

\begin{abstract}
The radical azidoalkylation of alkenes that was initially developed with $\alpha$-iodoesters and $\alpha$-iodoketones was extended to other activated iodomethyl derivatives. By using iodomethyl aryl sulfones, the preparation of $\gamma$-azidosulfones was easily achieved. Facile conversion of these azidosulfones to homoallylic azides using a Julia-Kocienski olefination reaction is reported, making the whole process equivalent to the azidoalkenylation of terminal alkenes.
\end{abstract}

Keywords: radical reaction; azidoalkylation; carboazidation; sulfones; azides; Julia-Kocienski olefination

\section{Introduction}

Organic alkyl azides are highly versatile compounds for synthesis [1-4]. They are unreactive towards a broad range of reaction conditions but, under dedicated conditions, they may become nitrene [5] and aminyl radical precursors [6-11] as well as suitable substrates for Schmidt reaction [12-14], aza-Wittig [15] reaction, and 1,3-dipolar cycloaddition [16,17].

They are commonly prepared via nucleophilic substitution of halides and related electrophiles using inorganic azides [18]. For tertiary alkyl azides, the nucleophilic substitution approach is often difficult, and free radical processes have proven to be a very convenient alternative. Radical azidation reactions are run under mild conditions, and they are compatible with a broad range of functional groups [19-21]. The carboazidation of alkenes represents a particularly attractive method to transform terminal alkenes into functionalized alkyl azides [22]. It is performed under chain transfer conditions and has been employed as a key step in several alkaloids syntheses [20,23-29]. Alternatively, carboazidation using under transition metal catalysis has also been reported [30-34]. Except for one reaction involving $\mathrm{CCl}_{3} \mathrm{Br}$ [22], the reaction has mainly been used with $\alpha$-iodoesters and $\alpha$-iodoketones (Scheme 1I) under ditin [35,36] or triethylborane [37,38] mediation. More recently, a very efficient desulfitative approach was reported starting from $\alpha$-azidosulfonyl esters [26]. This approach is the best in terms of atom economy and efficiency, but it is less convenient to test the applicability of the method with a broad range of substituted radicals since every starting azide has to be prepared separately. The iodide approach remains very attractive in terms of availability of the starting material (the starting iodide and the azidating agents are either commercially available or easily prepared), and it can be easily used to introduce of variety of functional groups. Here, we report the extension of the carboazidation process for the preparation of azido-nitriles, -phosphonates, -phthalimides, and sulfones according to Scheme 1II. The reaction with sulfones is particularly attractive since it allows one to prepare homoallylic azides. 


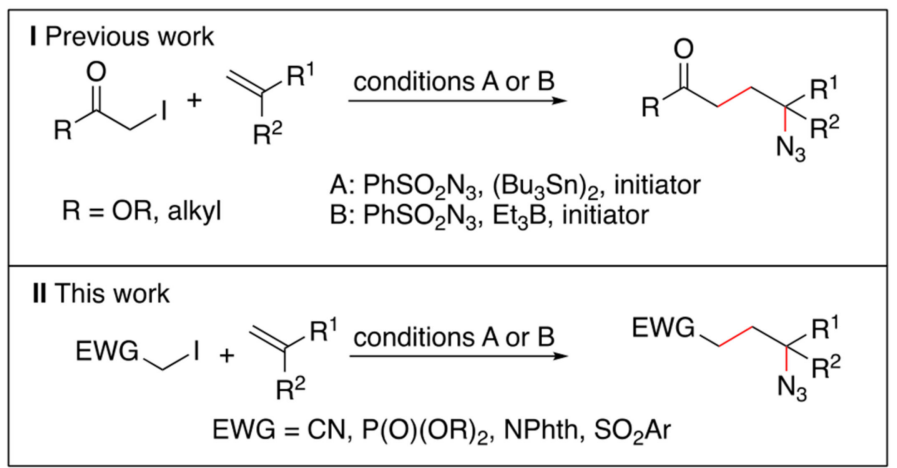

Scheme 1. The radical carboazidation reaction.

\section{Results}

Iodoacetonitrile 1, N-iodomethylphthalimide 2, diethyl iodomethanephosphonate 3, and iodomethyl phenyl sulfones 4 are either commercially available or easily prepared (see supporting information). They were tested for the carboazidation of terminal alkenes 5 under ditin (A) or triethylborane (B) conditions (Scheme 2). Under ditin-mediated conditions A, reactions of 1-4 with methylenecyclohexane 5a worked fine and provided the desired tertiary azide 6a-9a in good yields. Azidonitrile 6a is a potential precursor for 1,4-diamines, and azidophthalimide 7a is a bis-protected 1,3-diamine. $\gamma$-Azidophosphonates such as $\mathbf{8 a}$ are interesting precursors of $\gamma$-aminophosphonic acids, a well-established class of biologically active compounds [39]. Finally, the rich chemistry of sulfones renders $\gamma$-azidosulfones such as $9 \mathbf{a}$ as potential precursors for a broad range of functionalized amines. The reaction of iodomethylsulfone 4 with 5 a mediated by $\mathrm{Et}_{3} \mathrm{~B}$ (method B) provided the azidosulfones 9a in an increased $92 \%$ yield. Sulfone 4 was also employed for the carboazidation of methylenecycloheptene $\mathbf{5 b}$ and the two substituted methylenecyclohexanes $\mathbf{5} \mathbf{c}$ and $\mathbf{5 d}$ as well as the monosubstituted terminal alkene $\mathbf{5 e}$ under conditions B. The tertiary azides $\mathbf{9 b} \mathbf{b} \mathbf{9} \mathbf{d}$ were obtained in moderate to good yields, and the level of stereoselectivity observed for $9 \mathrm{c}$ and $9 \mathbf{d}$ (2-3:1) corresponded to expectations [40]. The secondary azidosulfone $9 \mathbf{e}$ was obtained in $45 \%$ yield under conditions B. The crude product was contaminated with the iodide $10 \mathrm{e}(9 \%)$ and the alcohol 11e (13\%). The alcohol 13e presumably resulted from a sulfone assisted hydrolysis of the iodide $\mathbf{1 0 e}$, but reaction of the intermediate radical with oxygen could not be excluded. When the reaction was run at a higher temperature according to method $\mathrm{A}$, no azide $9 \mathrm{e}$ was obtained, and the iodine atom transfer product $\mathbf{1 0 e}(34 \%$ yield) was the only isolated product. 


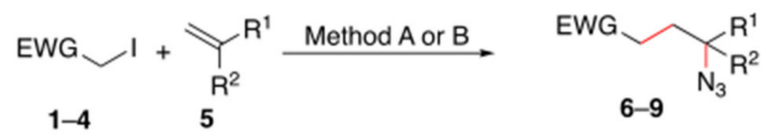

Method A: EWGCH${ }_{2} \mathrm{l}$, alkene (2 equiv), $\mathrm{ArSO}_{2} \mathrm{~N}_{3}$ (3 equiv), $\left(\mathrm{Bu}_{3} \mathrm{Sn}\right)_{2}$ (1.2 equiv), $t$-BuO $=\mathrm{NO} t-\mathrm{Bu}(0.1$ equiv), EtOAc, reflux

Method B: EWGCH $\mathrm{H}_{2}$, alkene (2 equiv), 3- $\mathrm{PySO}_{2} \mathrm{~N}_{3}$ (3 equiv), $\mathrm{Et}_{3} \mathrm{~B}$ (4 equiv), $\mathrm{CH}_{2} \mathrm{Cl}_{2}$, air, $\mathrm{rt}$

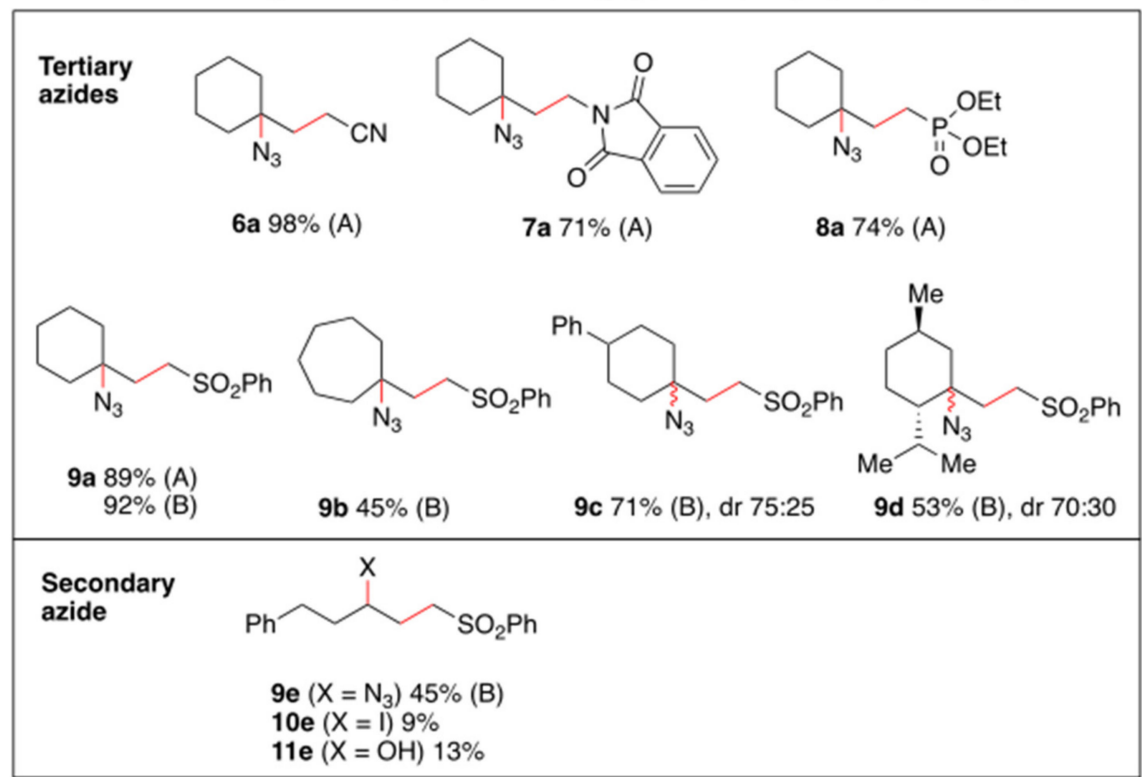

Scheme 2. Radical carboazidation with cyano-, phthalimido-, diethoxylphosphonyl-, and benzenesulfonyl-substituted radicals.

To illustrate the utility of $\gamma$-azidosulfones, compound $9 \mathrm{c}$ was sulfurized to $\mathbf{1 2}$ by treatment with lithium hexamethyldisilazane (LiHMDS) and diphenyl disulfide (PhSSPh). The sulfide 12 was easily converted to the unsaturated $\gamma$-azido vinyl sulfone 13, an attractive and versatile building block for synthesis, upon oxidation to the sulfoxide and standing in $\mathrm{CDCl}_{3}$ (Scheme 3). The whole reaction sequence allowed us to convert a terminal 2,2-disubsituted alkene into a tertiary 1-sufonylated allylic azide. Attempts to convert 12 into a $\beta$-azido ester upon treatment successively with meta-chloroperbenzoic acid ( $m$-CPBA) and trifluoroacetic acid (TFA) to promote a Pummerer rearrangement according to a procedure reported by Barton and co-workers failed to give the desired product [41].

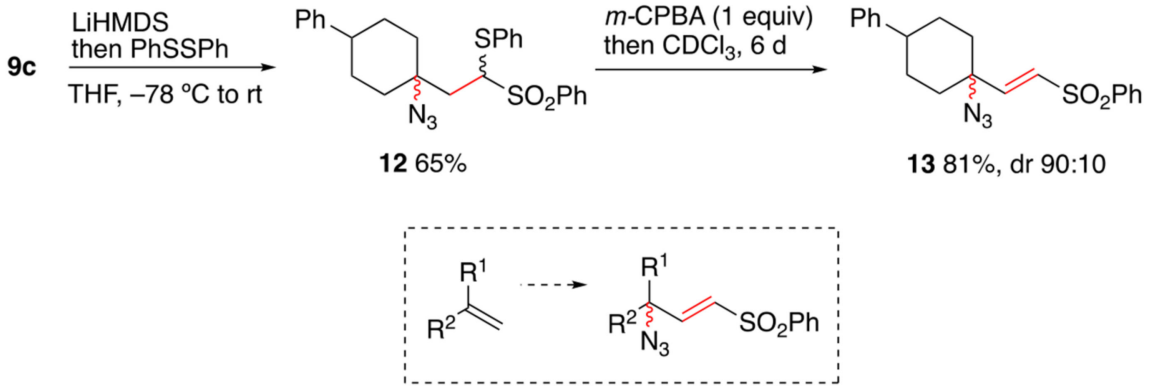

Scheme 3. Preparation of unsaturated $\gamma$-azido vinyl sulfone $\mathbf{1 3}$ from the azidosulfone $\mathbf{9 c}$.

The carboazidation with sulfones also offers a potential approach for the preparation of homoallylic azides [42] by taking advantage of the Julia-Kocienski olefination process [43,44]. For this purpose, 1-phenyl-1H-tetrazole-5-yl iodomethyl sulfone $\mathbf{1 4}$ was prepared from the commercially available 1-phenyl-1H-tetrazole-5-thiol $[45,46]$. Carboazidation was then tested with methylene cyclohexene 5a and 2-butyl-1-hexene $\mathbf{5 f}$ using the ditin procedure (Scheme 4). With $\mathbf{5 a}$, the tertiary azide 15a 
was obtained in high yield. The reaction with 2-butyl-1-hexene $5 f$ proved to be more challenging. The desired azide $\mathbf{1 5} \mathbf{f}$ was isolated in $31 \%$ yield together with a side product identified as being $\mathbf{1 6 f}$ in $20 \%$ yield. Compound $\mathbf{1 6 f}$ most likely resulted from the ipso attack of a tin radical to the $1 H$-tetrazole-5-yl sulfone followed by reaction of the primary alkanesulfonyl radical with 3-pyridinesulfonyl azide. A related intermolecular ipso substitution was recently reported by Kamijo and co-workers [47].
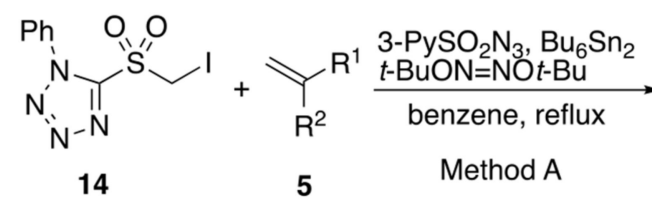

benzene, reflux

Method A

5

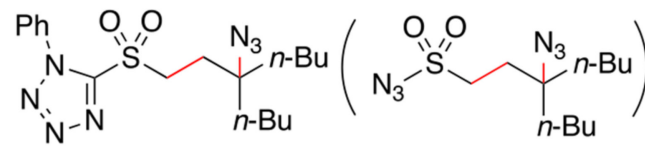

$15 f 31 \%$
$16 f 20 \%$<smiles>NC1(CCS(=O)(=O)c2nnnn2-c2ccccc2)CCCCC1</smiles>

15a $90 \%$

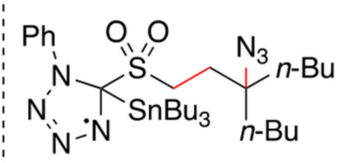

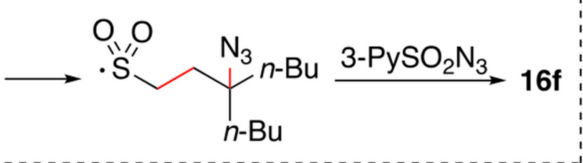

Scheme 4. Tin mediated azidoalkylation with 1-phenyl-1H-tetrazole-5-yl iodomethyl sulfone 14.

Following this observation, all carboazidation reactions involving $\mathbf{1 4}$ and different alkenes $\mathbf{5}$ were using the $\mathrm{Et}_{3} \mathrm{~B}$ method B. Results are summarized in Scheme 5, and moderate to good yields were observed for the formation of $\gamma$-azidosulfones 15 with a broad range of 2,2-substituted alkenes. No side product resulting from an ipso substitution at the tetrazole could be detected in those reactions. The radical nature of the process was demonstrated by formation of the ring-opening reaction product 15j from (-)- $\beta$-pinene.

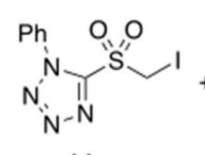

14

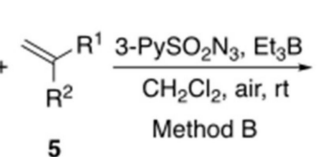

5<smiles>CC(C)(N)CCS(=O)(=O)c1nnn[nH]1</smiles>

15

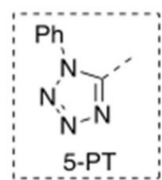

5-PT<smiles>NC1(CCOP(=O)(S)S)CCCC1</smiles>

$15 g 50 \%$<smiles>NC1(CCO[Se])CCC(c2ccccc2)CC1</smiles>

15 c $65 \%$, dr $75: 25$ 15a $72 \%$<smiles>CCOC(=O)CCC1CCCCC1(N)CCOC(=O)O[Sb]</smiles>

15i $65 \%$, dr 60:40<smiles>NC1(CCOP(=S)(S)S)CCCCCC1</smiles>

15b $55 \%$<smiles>NC1(CCO[Pb])CCCCCCC1</smiles>

15h $63 \%$

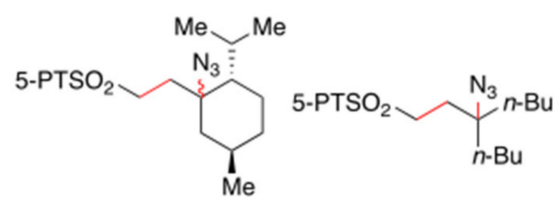

15d $46 \%$, dr $70: 30$

$15 f 48 \%$

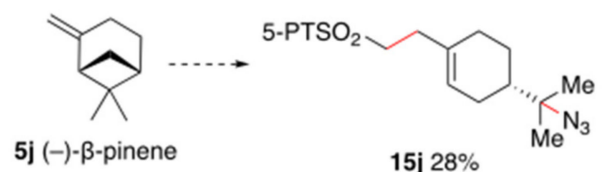

Scheme 5. Cont. 


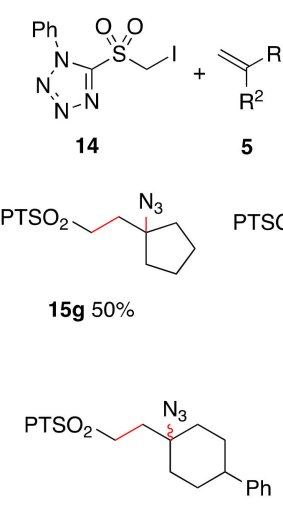

15c $65 \%$, dr 75:25
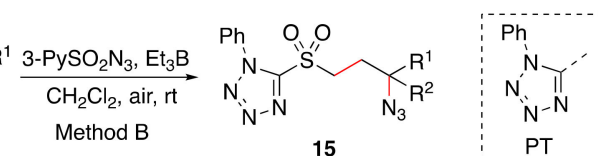<smiles>NC1(CCO[AsH3])CCCCC1</smiles>

15a $72 \%$

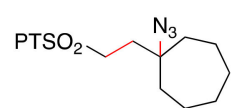

15b $55 \%$

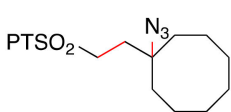

15h $63 \%$

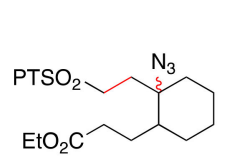

15i $65 \%$, dr $60: 40$

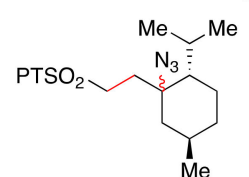

15d $46 \%$, dr $70: 30$

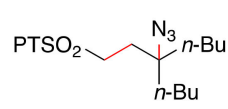

$15 f 48 \%$

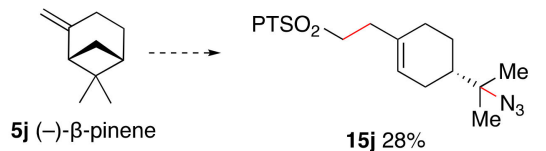

Scheme 5. $\mathrm{Et}_{3} \mathrm{~B}$ mediated azidoalkylation with 1-phenyl-1H-tetrazole-5-yl iodomethyl sulfone 14.

Finally, the 1-phenyl-1H-tetrazole sulfones 15 were submitted to the Julia-Kocienski olefination. Deprotonation of the sulfones 15 with LiHMDS followed by treatment with aldehydes afforded the homoallylic tertiary azides 17-21. Moderate to good yields and high $E$ selectivity were obtained with aromatic $(\mathbf{1 7})$, aliphatic $(\mathbf{1 8}, \mathbf{1 9})$, and $\alpha, \beta$-unaturated $(\mathbf{2 0}, \mathbf{2 1})$ aldehydes (Scheme 6). Interestingly, the homoallylic tertiary azides 17-21 were found to be stable and easily purified by column chromatography on silicagel.
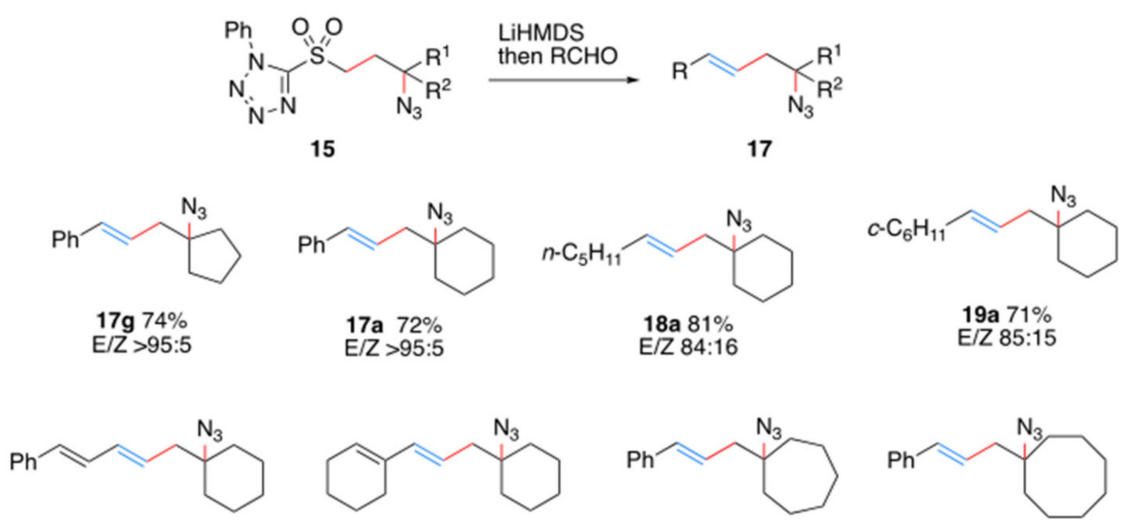

$20 \mathrm{a} 88 \%$
$\mathrm{E} / \mathrm{Z} 82: 18$

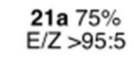

$17 \mathrm{~b} 88 \%$

$17 h$ h 66
$0 / Z 86: 14$
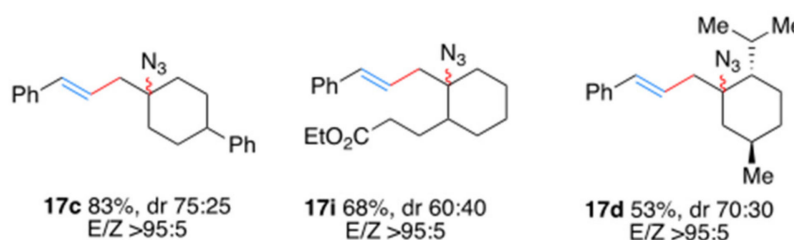

17d $53 \%$, dr $70: 30$ $E / Z>95: 5$
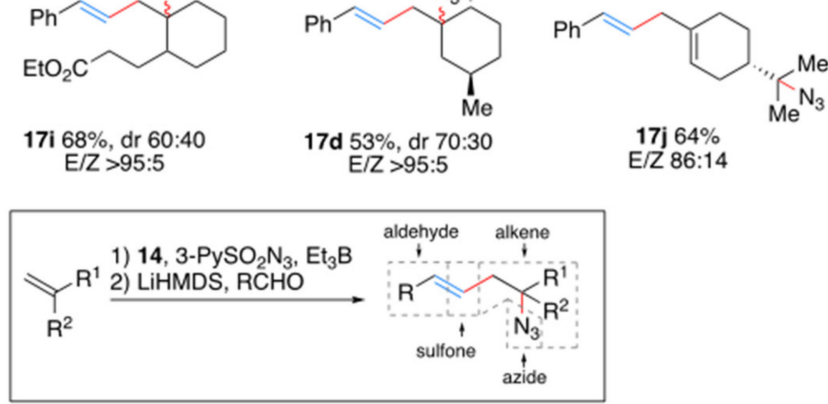

Scheme 6. Julia-Kocienski olefination of $\gamma$-azidosulfones 15 with aldehydes, a formal 4-component azidovinylation of alkenes. 


\section{Experimental Procedures}

\subsection{General Methods}

All glassware was oven-dried at $160{ }^{\circ} \mathrm{C}$ and assembled hot or flame dried under vacuum, and allowed to cool under a nitrogen atmosphere. Unless otherwise stated, all the reactions were performed under a nitrogen atmosphere. For flash chromatography (FC) silica gel P60 (40-63 $\mu \mathrm{m})$ (Silicycle, Basel, Switzerland) was used. Thin layer chromatography (TLC) was performed on silica gel F-254 plates (Silicycle, Basel, Switzerland) visualisation under UV (254 nm) or by staining. Staining solutions: (1) $\mathrm{KMnO}_{4}(1.5 \mathrm{~g}), \mathrm{K}_{2} \mathrm{CO}_{3}(10 \mathrm{~g})$ and $\mathrm{NaOH} 10 \%(1.25 \mathrm{~mL})$ in $\mathrm{H}_{2} \mathrm{O}(200 \mathrm{~mL})$; (2) ammonium molybdate tetrahydrate $(50 \mathrm{~g}), \mathrm{CeSO}_{4}(2 \mathrm{~g})$ and conc. $\mathrm{H}_{2} \mathrm{SO}_{4}(100 \mathrm{~mL})$ in $\mathrm{H}_{2} \mathrm{O}(900 \mathrm{~mL})$; (3) p-anisaldehyde $(3.7 \mathrm{~mL})$, acetic acid $(1.5 \mathrm{~mL})$ and conc. $\mathrm{H}_{2} \mathrm{SO}_{4}(5 \mathrm{~mL})$ in $\mathrm{EtOH}(135 \mathrm{~mL}) .{ }^{1} \mathrm{H}$ and ${ }^{13} \mathrm{C}$ NMR spectra were recorded on a Bruker Advance $300\left({ }^{1} \mathrm{H}: 300.18 \mathrm{MHz},{ }^{13} \mathrm{C}: 75.48 \mathrm{MHz}\right.$ ) (Bruker BioSpin AG, Fällanden, Switzerland). Chemical shifts (d) were reported in parts per million (ppm) with the residue solvent peak used as internal standard $\left(\mathrm{CHCl}_{3}: \mathrm{d}=7.26\right.$ ppm, $\mathrm{C}_{6} \mathrm{H}_{6}: \mathrm{d}=7.16$ ppm and THF: $\mathrm{d}=1.72 \mathrm{ppm}$ for ${ }^{1} \mathrm{H}$ NMR spectra and $\mathrm{CHCl}_{3}: \mathrm{d}=77.00$ ppm, $\mathrm{C}_{6} \mathrm{H}_{6}: \mathrm{d}=128.00$ ppm and THF: $\mathrm{d}=67.21$ ppm for ${ }^{13} \mathrm{C}$ NMR spectra). Multiplicities were abbreviated as follows: s (singlet), $d$ (doublet), $t$ (triplet), $\mathrm{q}$ (quadruplet), m (multiplet) and br (broad). Coupling constants $(J)$, are reported in $\mathrm{Hz} .{ }^{13} \mathrm{C} \mathrm{NMR}$ measurements were run using a proton-decoupled pulse sequence. The number of carbon atoms for each signal is indicated only when more than one. High-resolution mass spectrometry (HRMS) analyses were measured on an Applied Biosystems Sciex QSTAR Pulsar (hybrid quadrupole time-of-flight mass spectrometer using electrospray ionisation (ESI) (Sciex, Baden, Switzelrand). Low resolution mass-spectrometry (LRMS) analyses were performed Finnigan Trace GC-MS (Thermo Scientific, Schlieren, Switzerland) (EI mode at $70 \mathrm{eV}$ ); GC column: Optima Delta $30.25 \mu \mathrm{m}, 20 \mathrm{~m}, 0.25 \mathrm{~mm}$ (Macherey-Nagel, Oensingen, Switzerland). The infrared measurements were performed on a Jasco FTIR-460 Plus spectrometer equipped with a Specac MKII Golden Gate Single Reflection Diamond ATR System and are reported in wave numbers $\left(\mathrm{cm}^{-1}\right)$. All reagents were obtained from commercial sources and used without further purification, unless otherwise mentioned. All reactions solvents (distilled $\mathrm{THF}$, distilled $\mathrm{Et}_{2} \mathrm{O}$, distilled dichloromethane, commercial toluene and benzene) were filtered over columns of activated alumina under a positive pressure of argon. Solvents for flash chromatography and extractions were of technical grade and were distilled prior to use. Hexamethyldisilazane (HMDS) was fractionally distilled under a nitrogen atmosphere before use. 1,2-Dichloroethane (DCE) was distilled over $\mathrm{CaH}_{2}$ under a nitrogen atmosphere.

\subsection{General Procedures}

\section{Hexabutylditin-mediated carboazidation (procedure A)}

Di-tert-butyl hyponitrite (DTBHN) [48] (0.1 equiv) was added in one portion to a solution of alkene (2-4 equiv), iodomethyl derivative ( 1 equiv), $\left(\mathrm{Bu}_{3} \mathrm{Sn}\right)_{2}$ (1.2 equiv), and $\mathrm{ArSO}_{2} \mathrm{~N}_{3}$ [49] (3 equiv.) in benzene $(0.5 \mathrm{M})$. The solution was stirred at $70^{\circ} \mathrm{C}$ for $3 \mathrm{~h}$. The crude mixture was directly purified by flash chromatography (FC) using KF/silica [50].

\section{$\mathrm{Et}_{3} \mathrm{~B}$-mediated carboazidation (procedure B)}

A $1 \mathrm{M}$ solution of $\mathrm{Et}_{3} \mathrm{~B}$ (3-4 equiv) was added at room temperature (rt) over $2 \mathrm{~h}$ via syringe pump to an open flask and then charged with a vigorously stirred mixture of alkene (2-4 equiv), iodomethyl derivative (1 equiv), and 3- $\mathrm{PySO}_{2} \mathrm{~N}_{3}$ [49] (3 equiv) in solvent (0.66 M). Caution: the needle should be immersed into the reaction mixture in order to avoid direct contact of $\mathrm{Et}_{3} \mathrm{~B}$ drops with air. The reaction vessel should be protected from direct light exposure by aluminum foil. After $1 \mathrm{~h}$ stirring, $\mathrm{H}_{2} \mathrm{O}$ and $\mathrm{CH}_{2} \mathrm{Cl}_{2}$ were added, and the layers were separated. The aqueous layer was extracted with $\mathrm{CH}_{2} \mathrm{Cl}_{2}$ $(3 \times)$. The combined organic layers were washed with brine and dried over $\mathrm{Na}_{2} \mathrm{SO}_{4}$. The solvent was removed under reduced pressure, and the crude product was purified by FC. 


\section{Julia-Kocienski olefination}

The phenyltetrazole sulfone derivative (1 equiv) was dissolved/diluted in THF $(0.15 \mathrm{M})$ and cooled to $-78{ }^{\circ} \mathrm{C}$. A freshly prepared LiHMDS solution in THF (1.5 equiv) was added slowly and stirred for a further $30 \mathrm{~min}$ at $-78^{\circ} \mathrm{C}$. Aldehyde ( 2 equiv) was added neat and stirred for a further $3 \mathrm{~h}$ at $-78{ }^{\circ} \mathrm{C}$. The reaction mixture was allowed to reach $\mathrm{rt}$ and was further stirred at $\mathrm{rt}$ overnight. $\mathrm{H}_{2} \mathrm{O}$ and $\mathrm{Et}_{2} \mathrm{O}$ were added to the reaction suspension, and the layers were separated. The aqueous phase was extracted with $\mathrm{Et}_{2} \mathrm{O}(3 \times)$. The combined organic layers were washed with brine and dried over $\mathrm{Na}_{2} \mathrm{SO}_{4}$. The solvent was removed under reduced pressure, and the crude product was purified by FC.

5-((2-(1-Azidocyclohexyl)ethyl)sulfonyl)-1-phenyl-1H-tetrazole (15a)

According to the procedure A from di-tert-butylhyponitrite $(17 \mathrm{mg}, 0.10 \mathrm{mmol})$, methylenecyclohexane $5 \mathrm{a}(0.24 \mathrm{~mL}, 2.00 \mathrm{mmol}), 5$-((iodomethyl)sulfonyl)-1-phenyl-1H-tetrazole 14 (350 mg, $1.00 \mathrm{mmol})$, hexabutylditin $(0.61 \mathrm{~mL}, 1.20 \mathrm{mmol})$, and $3-\mathrm{PySO}_{2} \mathrm{~N}_{3}(552 \mathrm{mg}, 3.00 \mathrm{mmol})$ in benzene $(2.0 \mathrm{~mL})$. The crude mixture was directly purified by FC using KF/silica gel (cyclohexane/EtOAc, 95:5) to afford 15a (325 $\mathrm{mg}, 90 \%)$.

According to the procedure $\mathrm{B}$ from a $1 \mathrm{M}$ solution of $\mathrm{Et}_{3} \mathrm{~B}$ in $\mathrm{CH}_{2} \mathrm{Cl}_{2}(4.00 \mathrm{~mL}, 4.00 \mathrm{mmol})$, methylenecyclohexane $5 \mathrm{a}(0.24 \mathrm{~mL}, 2.00 \mathrm{mmol}), 5$-((iodomethyl)sulfonyl)-1-phenyl-1H-tetrazole 14, (350 mg, $1.00 \mathrm{mmol})$, 3-PySO ${ }_{2} \mathrm{~N}_{3}(552 \mathrm{mg}, 3.00 \mathrm{mmol})$, and $\mathrm{CH}_{2} \mathrm{Cl}_{2}(0.50 \mathrm{~mL})$. Purification by $\mathrm{FC}$ (cyclohexane/EtOAc, 95:5) afforded 15a (260 mg, 72\%). The NMR spectra of some compounds are in the Supplementary Materials.

Colorless crystals: m.p. $90.9-93.6{ }^{\circ} \mathrm{C} .{ }^{1} \mathrm{H}$ NMR $\left(300 \mathrm{MHz}, \mathrm{CDCl}_{3}\right): \delta=7.76-7.72(\mathrm{~m}, 2 \mathrm{H}), 7.69-7.62(\mathrm{~m}$, $3 \mathrm{H}), 3.90-3.84(\mathrm{~m}, 2 \mathrm{H}), 2.24-2.18(\mathrm{~m}, 2 \mathrm{H}), 1.81-1.73(\mathrm{~m}, 2 \mathrm{H}), 1.69-1.29(\mathrm{~m}, 8 \mathrm{H}) .{ }^{13} \mathrm{C}$ NMR $(75 \mathrm{MHz}$, $\left.\mathrm{CDCl}_{3}\right): \delta=153.31,132.96,131.50,129.75$ (2C), $125.00(2 \mathrm{C}), 62.45,51.61,34.41$ (2C), 31.72, 25.07, 21.96 (2C). IR (neat): 2933, 2856, 2098, 1497, 1337, 1253, 1150. HRMS (ESI): calcd. for [M+ H] ${ }^{+}: \mathrm{C}_{15} \mathrm{H}_{20} \mathrm{~N}_{7} \mathrm{O}_{2} \mathrm{~S}$ calcd 362.1394; found: 362.1400 .

\section{(3-(1-Azidocyclohexyl)prop-1-en-1-yl)benzene (17a)}

According to the Julia-Kocienski procedure from 15a (260 mg, $0.72 \mathrm{mmol})$, LiHMDS in THF $(1.66 \mathrm{~mL}, 1.08 \mathrm{mmol})$, benzaldehyde $(0.15 \mathrm{~mL}, 1.44 \mathrm{mmol})$, and THF $(3.00 \mathrm{~mL})$. Purification by FC (cyclohexane/EtOAc, 98:2) afforded the alkene 17a as an inseparable mixture of isomers (141 mg, E/Z > 95:5, 81\%). Colorless oil.

(E)-17a (major): ${ }^{1} \mathrm{H}$ NMR $\left(300 \mathrm{MHz}, \mathrm{CDCl}_{3}\right): \delta=7.39-7.20(\mathrm{~m}, 5 \mathrm{H}), 6.47(\mathrm{~d}, J=15.8 \mathrm{~Hz}, 1 \mathrm{H}), 6.24(\mathrm{dt}$, $J=15.8,7.4 \mathrm{~Hz}, 1 \mathrm{H}), 2.46(\mathrm{dd}, J=7.4,1.2 \mathrm{~Hz}, 2 \mathrm{H}), 1.72(\mathrm{~d}, J=13.1 \mathrm{~Hz}, 2 \mathrm{H}), 1.65-1.39(\mathrm{~m}, 7 \mathrm{H}), 1.32-1.21$ $(\mathrm{m}, 1 \mathrm{H}) .{ }^{13} \mathrm{C} \mathrm{NMR}\left(75 \mathrm{MHz}, \mathrm{CDCl}_{3}\right):=137.24,133.74,128.51(2 \mathrm{C}), 127.29,126.17(2 \mathrm{C}), 124.36,64.22$, $43.93,34.52(2 \mathrm{C}), 25.33,22.07(2 \mathrm{C})$.

Characteristic signals for (Z)-17a (minor): ${ }^{1} \mathrm{H}$ NMR (300 MHz, $\left.\mathrm{CDCl}_{3}\right): \delta=2.55(\mathrm{~d}, J=5.8 \mathrm{~Hz}, 2 \mathrm{H})$. IR (neat): 3027, 2931, 2858, 2096, 1495, 1447, 1254, 1138, 1102, 1029. EI-MS m/z (\%): M-N $2: 213.3$ (21), 198.3 (7), 170.3 (20), 156.3 (16), 128.3 (10), 117.3 (100), 115.3 (73), 96.3 (63), 91.3 (40), 69.3 (34), 55.3 (39). HRMS (ESI): calcd. for [M+ H] ${ }^{+}: \mathrm{C}_{15} \mathrm{H}_{20} \mathrm{~N}_{3}$ : 242.1652; found: 242.1655 .

\section{Conclusions}

In conclusion, we demonstrated that the azidoalkylation of terminal alkenes is not limited to $\alpha$-iodoester and $\alpha$-iodoketones. The reaction also works well with nitriles, phosphonates, phthalimides, and aryl sulfones. This last class of compounds is particularly interesting in terms of potential synthetic applications. This point was illustrated by the preparation of homoallylic azides by merging the azidoalkylation process with a Julia-Kocienski olefination reaction. Recently, 1-phenyl-1H-tetrazole sulfones have also been shown to be privileged substrates for reductive cross-coupling processes, opening new opportunities for further functionalization [51,52]. 
Supplementary Materials: Detailed experimental procedures and NMR spectra of all compounds are available online at http://www.mdpi.com/1420-3049/24/22/4184/s1.

Author Contributions: Conceptualization and methodology, N.M., G.L. and P.R.; Experimental work N.M., G.L.; writing—original draft preparation, N.M.; Writing—review and editing, P.R.; Supervision, project administration and funding acquisition, P.R.

Funding: This research was funded by the Swiss National Science Foundation (Project 200020_172621).

Conflicts of Interest: The authors declare no conflict of interest.

\section{References}

1. Bräse, S.; Banert, K. Organic Azides: Syntheses and Applications; John Wiley \& Sons: Chichester, UK, 2010; ISBN 978-0-470-51998-1.

2. Tanimoto, H.; Kakiuchi, K. Recent applications and developments of organic azides in total synthesis of natural products. Nat. Prod. Commun. 2013, 8, 1021-1034. [CrossRef]

3. Chiba, S. Application of organic azides for the synthesis of nitrogen-containing molecules. Synlett 2012, 23, 21-44. [CrossRef]

4. Bräse, S.; Gil, C.; Knepper, K.; Zimmermann, V. Organic azides. An exploding diversity of a unique class of compounds. Angew. Chem. Int. Ed. 2005, 44, 5188-5240. [CrossRef]

5. Gritsan, N.; Platz, M. Photochemistry of azides: The azide/nitrene interface. In Organic Azides-Syntheses and Applications; Bräse, S., Banert, K., Eds.; John Wiley \& Sons: Chichester, UK, 2010; pp. 311-372. ISBN 978-0-470-68251-7.

6. Kim, S. Radical cyclizations involving the evolution of nitrogen. Pure Appl. Chem. 1996, 68, 623-626. [CrossRef]

7. Kim, S.; Joe, G.H.; Do, J.Y. Novel radical cyclizations of alkyl azides. A new route to N-Heterocycles. J. Am. Chem. Soc. 1994, 116, 5521-5522. [CrossRef]

8. Montevecchi, P.C.; Navacchia, M.L.; Spagnolo, P. A study of vinyl radical cyclization onto the azido group by addition of sulfanyl, stannyl, and silyl radicals to alkynyl azides. Eur. J. Org. Chem. 1998, 1219-1226. [CrossRef]

9. Wyler, B.; Brucelle, F.; Renaud, P. Preparation of the core structure of aspidosperma and strychnos alkaloids from aryl azides by a cascade radical cyclization. Org. Lett. 2016, 18, 1370-1373. [CrossRef] [PubMed]

10. Brucelle, F.; Renaud, P. Synthesis of a leucomitosane via a diastereoselective radical cascade. J. Org. Chem. 2013, 78, 6245-6252. [CrossRef] [PubMed]

11. Minozzi, M.; Nanni, D.; Spagnolo, P. From azides to nitrogen-centered radicals: Applications of azide radical chemistry to organic synthesis. Chem. Eur. J. 2009, 15, 7830-7840. [CrossRef] [PubMed]

12. Wrobleski, A.; Coombs, T.C.; Huh, C.W.; Li, S.-W.; Aubé, J. The Schmidt reaction. Org. React. 2012, 78, 1-320.

13. Aubé, J.; Fehl, C.; Liu, R.; McLeod, M.C.; Motiwala, H.F. Hofmann, Curtius, Schmidt, Lossen, and related reactions. Compr. Org. Synth. 2014, 6, 598-635.

14. Nyfeler, E.; Renaud, P. Intramolecular Schmidt reaction: Applications in natural product synthesis. CHIMIA Int. J. Chem. 2006, 60, 276-284. [CrossRef]

15. Palacios, F.; Alonso, C.; Aparicio, D.; Rubiales, G.; de los Santos, J.M. Aza-Wittig reaction in natural product syntheses. In Organic Azides; Wiley: Chichester, UK, 2010; pp. 437-467. ISBN 978-0-470-68251-7.

16. Binder, W.H.; Kluger, C. Azide/alkyne-"click" reactions: Applications in material science and organic synthesis. Curr. Org. Chem. 2006, 10, 1791-1815. [CrossRef]

17. Schilling, C.; Jung, N.; Bräse, S. Cycloaddition Reactions with azides: An overview. In Organic Azides-Syntheses and Applications; Bräse, S., Banert, K., Eds.; John Wiley \& Sons: Chichester, UK, 2010; pp. 269-284. ISBN 978-0-470-68251-7.

18. Pinho e Melo, T.M.V.D. Synthesis of azides. In Organic Azides—Syntheses and Applications; Bräse, S., Banert, K., Eds.; John Wiley \& Sons: Chichester, UK, 2010; pp. 53-94. ISBN 978-0-470-68251-7.

19. Jimeno, C.; Renaud, P. Radical chemistry with azides. In Organic Azides-Syntheses and Applications; Bräse, S., Banert, K., Eds.; John Wiley \& Sons: Chichester, UK, 2010; pp. 239-267. ISBN 978-0-470-68251-7.

20. Lapointe, G.; Kapat, A.; Weidner, K.; Renaud, P. Radical azidation reactions and their application in the synthesis of alkaloids. Pure Appl. Chem. 2012, 84, 1633-1641. [CrossRef] 
21. Panchaud, P.; Chabaud, L.; Landais, Y.; Ollivier, C.; Renaud, P.; Zigmantas, S. Radical amination with sulfonyl azides: A powerful method for the formation of CN bonds. Chem. Eur. J. 2004, 10, 3606-3614. [CrossRef]

22. Renaud, P.; Ollivier, C.; Panchaud, P. Radical carboazidation of alkenes: An efficient tool for the preparation of pyrrolidinone derivatives. Angew. Chem. Int. Edit. 2002, 41, 3460-3462. [CrossRef]

23. Panchaud, P.; Ollivier, C.; Renaud, P.; Zigmantas, S. Radical carboazidation: Expedient assembly of the core structure of various alkaloid families. J. Org. Chem. 2004, 69, 2755-2759. [CrossRef]

24. Chabaud, L.; Landais, Y.; Renaud, P. Total synthesis of hyacinthacine A(1) and 3-epi-hyacinthacine A(1). Org. Lett. 2005, 7, 2587-2590. [CrossRef]

25. Schär, P.; Renaud, P. Total synthesis of the marine alkaloid (+/-)-lepadiformine via a radical carboazidation. Org. Lett. 2006, 8, 1569-1571. [CrossRef]

26. Weidner, K.; Giroult, A.; Panchaud, P.; Renaud, P. Efficient carboazidation of alkenes using a radical desulfonylative azide transfer process. J. Am. Chem. Soc. 2010, 132, 17511-17515. [CrossRef]

27. Lapointe, G.; Schenk, K.; Renaud, P. Concise synthesis of pyrrolidine and indolizidine alkaloids by a highly convergent three-component reaction. Chem. Eur. J. 2011, 17, 3207-3212. [CrossRef]

28. Lapointe, G.; Schenk, K.; Renaud, P. Total synthesis of ( \pm )-cylindricine C. Org. Lett. 2011, 13, 4774-4777. [CrossRef]

29. Gonçalves-Martin, M.G.; Zigmantas, S.; Renaud, P. Formal synthesis of (-)-cephalotaxine. Helv. Chim. Acta 2012, 95, 2502-2514. [CrossRef]

30. Huang, W.-Y.; Lü, L. The reaction of perfluoroalkanesulfinates VII. Fenton reagent-initiated addition of sodium perfluoroalkanesulfinates to alkenes. Chin. J. Chem. 1992, 10, 365-372. [CrossRef]

31. Wei, X.-H.; Li, Y.-M.; Zhou, A.-X.; Yang, T.-T.; Yang, S.-D. Silver-catalyzed carboazidation of arylacrylamides. Org. Lett. 2013, 15, 4158-4161. [CrossRef]

32. Bunescu, A.; Ha, T.M.; Wang, Q.; Zhu, J. Copper-catalyzed three-component carboazidation of clkenes with acetonitrile and sodium azide. Angew. Chem. Int. Ed. 2017, 56, 10555-10558. [CrossRef] [PubMed]

33. Li, W.-Y.; Wu, C.-S.; Wang, Z.; Luo, Y. Fe-Catalyzed three-component carboazidation of alkenes with alkanes and trimethylsilyl azide. Chem. Commun. 2018, 54, 11013-11016. [CrossRef] [PubMed]

34. Xiong, H.; Ramkumar, N.; Chiou, M.-F.; Jian, W.; Li, Y.; Su, J.-H.; Zhang, X.; Bao, H. Iron-catalyzed carboazidation of alkenes and alkynes. Nat. Commun. 2019, 10, 1-7. [CrossRef] [PubMed]

35. Ollivier, C.; Renaud, P. Formation of carbon-nitrogen bonds via a novel radical azidation process. J. Am. Chem. Soc. 2000, 122, 6496-6497. [CrossRef]

36. Ollivier, C.; Renaud, P. A novel approach for the formation of carbon - nitrogen bonds: Azidation of alkyl radicals with sulfonyl azides. J. Am. Chem. Soc. 2001, 123, 4717-4727. [CrossRef]

37. Panchaud, P.; Renaud, P. A convenient tin-free procedure for radical carboazidation and azidation. J. Org. Chem. 2004, 69, 3205-3207. [CrossRef] [PubMed]

38. Panchaud, P.; Renaud, P. 3-Pyridinesulfonyl azide. In Encyclopedia of Reagents for Organic Synthesis; John Wiley Sons, Ltd.: Chichester, UK, 2006; ISBN 978-0-470-84289-8.

39. Aminophosphonic and Aminophosphinic Acids: Chemistry and Biological Activity; Kukhar, V.P.; Hudson, H.R. (Eds.) John Wiley Sons, Ltd.: Chichester, UK, 2000; ISBN 978-0-471-89149-9.

40. Cren, S.; Schär, P.; Renaud, P.; Schenk, K. Diastereoselectivity control of the radical carboazidation of substituted methylenecyclohexanes. J. Org. Chem. 2009, 74, 2942-2946. [CrossRef] [PubMed]

41. Barton, D.H.R.; Chern, C.Y.; Jaszberenyi, J.C. The Invention of radical reactions. XXXIII. Homologation reactions of carboxylic acids by radical chain chemistry. Aust. J. Chem. 1995, 48, 407-425. [CrossRef]

42. Vita, M.V.; Caramenti, P.; Waser, J. Enantioselective synthesis of homoallylic azides and nitriles via palladium-catalyzed decarboxylative allylation. Org. Lett. 2015, 17, 5832-5835. [CrossRef] [PubMed]

43. Blakemore, P.R.; Cole, W.J.; Kocieński, P.J.; Morley, A. A stereoselective synthesis of trans-1,2-sisubstituted alkenes based on the condensation of aldehydes with metallated 1-phenyl-1H-tetrazol-5-yl sulfones. Synlett 1998, 1998, 26-28. [CrossRef]

44. Marko, I.; Pospisil, J. Julia, Julia-Kocienski, and related sulfur-based alkenations. In Category 6, Compounds with All-Carbon Functions, Science of Synthesis; Neier, R., Bellus, D., Eds.; G. Thieme Verlag: Stuttgart, Germany, 2010; Volume 47a, ISBN 978-3-13-119011-6.

45. Lebrun, M.-E.; Le Marquand, P.; Berthelette, C. Stereoselective synthesis of Z alkenyl halides via Julia olefination. J. Org. Chem. 2006, 71, 2009-2013. [CrossRef] [PubMed] 
46. Wang, X.; Bowman, E.J.; Bowman, B.J.; Porco, J.A. Total synthesis of the salicylate enamide macrolide oximidine III: Application of relay ring-closing metathesis. Angew. Chem. Int. Ed. 2004, 43, 3601-3605. [CrossRef]

47. Kamijo, S.; Kamijo, K.; Murafuji, T. Aryl ketone mediated photoinduced radical coupling for the alkylation of benzazoles employing saturated heterocyclic compounds. Synthesis 2019, 51, 3859-3864.

48. David Mendenhall, G. The Lewis acid catalyzed reaction of trans-hyponitrite ion with alkyl halides. Tetrahedron Lett. 1983, 24, 451-452. [CrossRef]

49. Panchaud, P.; Renaud, P. 3-Pyridinesulfonyl azide: A useful reagent for radical azidation. Adv. Synth. Catal. 2004, 346, 925-928. [CrossRef]

50. Harrowven, D.C.; Guy, I.L. KF-Silica as a stationary phase for the chromatographic removal of tin residues from organic compounds. Chem. Commun. 2004, 1968-1969. [CrossRef] [PubMed]

51. Merchant, R.R.; Edwards, J.T.; Qin, T.; Kruszyk, M.M.; Bi, C.; Che, G.; Bao, D.-H.; Qiao, W.; Sun, L.; Collins, M.R.; et al. Modular radical cross-coupling with sulfones enables access to sp3-rich (fluoro)alkylated scaffolds. Science 2018, 360, 75-80. [CrossRef] [PubMed]

52. Hughes, J.M.E.; Fier, P.S. Desulfonylative arylation of redox-active alkyl sulfones with aryl bromides. Org. Lett. 2019, 21, 5650-5654. [CrossRef] [PubMed]

Sample Availability: Samples are not available from the authors. 